\title{
The devil is in the details
}

\author{
Ho Manh Toan \\ AISDL
}

Hanoi, 25-10-2020

During my first year as a researcher, most of my time was spent on entering data for the SSHPA database [1]. At the moment, I have produced eight publications from the SSHPA data, which include my very first paper [2], and two successful collaborations with my 'kouhai' $[3,4]$.

The SSHPA system was designed by my mentor, Dr. Vuong Quan Hoang, and coded by Mr. La Viet Phuong - the sole software engineer in the team, the details can be read in [1]. Once the most challenging part was solved, the remained work was entering data manually. Indeed, the work is not too hard. A high school student with 2-hour guidance can start entering immediately. However, as the old saying, "the devil is in the details," the horror of the work lies in the details of data. Regardless of who you are, you have to meticulously go through the same steps for every entry (article or author or affiliation or publisher). The repeated nature can make people impatient easily. And once you are impatient, you are more prone to mistake.

Thus, the data input process becomes a test of virtue-patience, meticulousness, attentiveness, carefulness. Thus, the work seems like a natural fit for young students, and eventually, those who survive will be rewarded generously. We continue to maintain the database. However, one project opens doors to others.

Dr. Ngo Bao Chau spent six years developing a 169-page proof for the fundamental lemma for Lie algebras and the non-standard fundamental lemma [5]. His work earned him everything. And even though the comparison is uneven, my time with the SSHPA earned me a chance to work on Dr. Ngo's project [6]. This time, same philosophy, same spirit, but in a different field: Mathematics. We hope to be able to draw a beautiful picture of Vietnam's mathematics with the SciMath data [6], just as we did with Vietnam's social sciences and humanities and the SSHPA data [1].

It is hard to quantify the impact of our databases now. However, we believe that our works have contributed a cheap solution to a national matter [7]. So far, all we did was working hard.

\section{References}

[1] Vuong, Q. H., La, V. P., Vuong, T. T., Ho, M. T. et al. (2018). An open database of productivity in Vietnam's social sciences and humanities for public use. Scientific Data, 5, 180188, DOI:10.1038/sdata.2018.188. 
[2] Vuong, T. T., Nguyen, T. H. K., Ho, M. T., Ho, M. T. and Vuong, Q. H. (2018). The (in)significance of socio-demographic factors as possible determinants of Vietnamese social scientists' contribution-adjusted productivity: Preliminary results from 2008-2017 Scopus data. Societies, 8(1), 3 DOI: 10.3390/soc8010003.

[3] Vuong, T. T., Ho, M. T., Nguyen, M. H., Nguyen, T. T. H. et al. (2020). Adopting open access in the social sciences and humanities: evidence from a developing nation. Heliyon, 6(7), e04522, DOI: 10.1016/j.heliyon.2020.e04522.

[4] Ho, M. T., Vuong, T. T., Pham, T. H., Luong, A. P. et al. (2020). The internal capability of Vietnam social sciences and humanities: A perspective from the 2008-2019 dataset. Publications, 8(2), 32, DOI: 10.3390/publications8020032.

[5] Ngo, B. C. (2010). Le lemme fondamental pour les algebres de Lie. Publications Mathématiques de I'IHÉS, 111(1), 1-169.

[6] Ngo, B. C, Vuong, Q. H., La, V. P., Le, T. H. et al. (2020). The 80-year development of Vietnam mathematical research: Preliminary insights from the SciMath database on mathematicians, their works and their networks. arXiv preprint, arXiv:2011.09328.

[7] Vuong, Q. H. (2018). The (ir) rational consideration of the cost of science in transition economies. Nature Human Behaviour, 2(1), 5 